\title{
In vitro evaluation of antimicrobial activity of essential oils with potential application in biomaterial (castor oil based polyurethane)
}

\author{
E Watanabe $^{1 *}$, CG Maia ${ }^{2}$, DD Andrade ${ }^{1}$, \\ NEPECISS and Núcleo de Estudos de Prevenção e Controle de Infecção nos Serviços de Saúde (NEPECISS) ${ }^{1}$ \\ From International Conference on Prevention \& Infection Control (ICPIC 2011) \\ Geneva, Switzerland. 29 June - 2 July 2011
}

\section{Introduction / objectives}

Nowadays, with the multiresistant microorganisms and biofilm-related infections, diverse biomaterials with antimicrobial activity have been developed. The aim of this study was to evaluate the in vitro antimicrobial activity of essential oils with potential application in biomaterial made of the castor oil based polyurethane in this study supported by FAPESP (2010/50090-8) against reference microorganisms: S. aureus (ATCC 25923), MRSA (ATCC 43300), S. epidermidis (ATCC 14990), E. coli (ATCC 25922), P. aeruginosa (ATCC 27853) and C. albicans (ATCC 10231).

\section{Methods}

The culture medium was distributed in Petri plates (20x100mm) forming a base layer of $12 \mathrm{ml}$. After solidification of the medium, $8 \mathrm{ml}$ of medium containing microbial inoculum $1 \%$ in the range of 0.5 McFarland was distributed over the base layer to form the seed layer (seeded). On each plate were made five wells with diameters of $5 \mathrm{~mm}$. Aliquots of $20 \mu \mathrm{l}$ of the different essential oils were applied to each well. After the pre-incubation, the plates were incubated and the reading of the diameters of inhibition zones $(\mathrm{mm})$ performed.

\section{Results}

Essential oils with improved antimicrobial activity, in descending order, were those of the melaleuca, clove and rosemary. Moreover, the essential oils of the cedar and copaiba presented only antimicrobial activity against Gram-positive and the essential oil of the clove showed the best antimicrobial activity against $C$. albicans.

\section{Conclusion}

In conclusion, all essential oils showed antimicrobial activity and they could be used in biomaterial to infection control, highlighting the melaleuca, clove and rosemary. In addition, $P$. aeruginosa was the most resistant microorganism and MRSA the most sensitive to essential oils.

\section{Disclosure of interest}

None declared.

\section{Author details}

${ }^{1}$ Enfermagem Geral e Fundamental, Escola de Enfermagem de Ribeirão Preto - USP, Brazil. ${ }^{2}$ Universidade de Ribeirão Preto, Ribeirão Preto, Brazil.

Published: 29 June 2011

\section{doi:10.1186/1753-6561-5-S6-P43}

Cite this article as: Watanabe et al:: In vitro evaluation of antimicrobial activity of essential oils with potential application in biomaterial (castor oil based polyurethane). BMC Proceedings 2011 5(Suppl 6):P43.

${ }^{1}$ Enfermagem Geral e Fundamental, Escola de Enfermagem de Ribeirão Preto

- USP, Brazil

Full list of author information is available at the end of the article

(c) 2011 Watanabe et al; licensee BioMed Central Ltd. This is an open access article distributed under the terms of the Creative 